\title{
Power Supply Variabel Berbasis Arduino
}

\author{
Genta Subni Ananda Putra ${ }^{1}$, Ariza Nabila ${ }^{2}$, dan Ali Basrah Pulungan ${ }^{3}$ \\ 1,2,3 Universitas Negeri Padang \\ Jl Prof Dr Hamka Air Tawar, Padang, Indonesia \\ genta071096@gmail.com ${ }^{1}$,arizanabilaa21@gmail.com², alibp@ft.unp.ac.id ${ }^{3}$
}

\begin{abstract}
Power supply is a device used as a power provider for one or more electrical loads. For this reason, it requires a power supply whose output voltage can be adjusted according to the load used. The purpose of making this final project is to be able to design and create a power supply whose output voltage can be adjusted easily as desired. This tool can change the AC voltage of $220 \mathrm{~V}$ into a $D C$ voltage of $5 \mathrm{~V}$ for a voltage source on the Arduino using a rectifier circuit, when the voltage is input via the keypad, Arduino will process and give an instruction to the DAC module via I2C on the LCD to output the voltage according to the input from the keypad.
\end{abstract}

Keywords-Power supply, DAC, arduino uno.

Abstrak-Power supply merupakan alat yang digunakan sebagai penyedia daya untuk satu atau lebih beban lisrik. Untuk itu dibutuhkan power supply yang keluaran tegangannya dapat diatur sesuai dengan beban yang di gunakan. Tujuan dari pembuatan proyek akhir ini yaitu dapat merancang dan membuat power supply yang keluaran tegangannya dapat diatur dengan mudah sesuai yang di inginkan. Alat ini dapat mengubah tegangan AC $220 \mathrm{~V}$ menjadi tegangan DC 5V untuk sumber tegangan pada arduino dengan menggunakan rangkaian penyearah, pada saat tegangan di inputkan melalui keypad maka arduino akan memproses dan memberikan perintah instuksi kepada modul DAC melalui I2C pada LCD untuk mengeluarkan tegangan sesuai dengan input dari keypad.

Kata kunci- Power supply, DAC, arduino uno.

\section{Pendahuluan}

Pada saat sekarang ini penggunaan elektronika daya semakin meluas dan merupakan bagian yang sangat penting pada banyak bidang. Oleh karena itu pengembangan elektronika daya perlu terus dilakukan pengembangan. Salah satu bagian dari pengembangan elektronika daya tersebut adalah power supply. Power supply (catu daya) adalah suatu rangkaian elektronik yang mengubah arus listrik AC (bolak - balok) menjadi arus listrik DC (searah). Power supply merupakan sebuah peralatan yang berfungsi sebagai penyedia daya untuk peralatan lainnya [1].

Jenis jenis power supply antara lain DC power supply, Ac power supply dan switch mode power supply. DC power supply adalah catu daya yang menyediakan tegangan maupun arus listrik dalam bentuk DC dan memiliki polaritas yang tetap yaitu positif dan negatif. $A C$ power supply berguna untuk mengubah sumber tegangan AC ke taraf tegangan taraf lainnya dan switch mode power supply berguna untuk menyearahkan dan menyaring tegangan input AC untuk mendapatkan tegangan DC [2][3].

Seiring dengan perkembangan teknologi di bidang elektronika daya maka peranangannya pun mengalami perkembangan seperti yang di buat oleh Alif Ya Franko dengan judul "Rancang Bangun Catu Daya DC 0V - 24V 3A" dalam perancangan ini mengunakan potensio sebagai pengendali tegangan kelurannya dan mengunakan mikrokontroller ATmega 8 sebagai pusat pengendali utama dari catu daya. Salah satu dari kelemahan alat ini adalah dikarenakan menggunakan potensio sebagai pengendali keluaran tegangan maka mengalami kesulitan untuk pengaturan keluaran tegangan yang pas. Cahyadi dkk, Rancang bangun catu daya DC 1V - $20 \mathrm{~V}$ menggunakan kendali P-I berbasis mikrokontroler, dalam perancangan ini menggunakan Mikrokontroler ATmega 8535 sebagai device utamanya [4][5].

Perbedaan utama dari alat yang di buat ini digunakannya keypad sebagai pengendali besar keluaran tegangan yang diinginkan sehingga tegangan output yang dikeluarkan lebih akurat dan ditampilkan dilayar LCD serta meggunakan arduino uno sebagai pusat pengendaliannya.

\section{Metode}

Pada perancangan alat ini prinsip kerja alat diatur menggunakan keypad yang terprogram ke arduino uno sebagai kontrol utama. Alat ini bekerja dengan cara ketika power supply akan menyupply tegangan pada beban, maka kita dapat menggunakan keypad sebagai pengaturan tegangan output nya, tegangan dan arus akan memuncukan keterangan atau pemberitahuan tampil pada LCD. Kita dapat menambahkan beban sesuai kebutuhan dengan syarat tidak melebihi kapasitas yang telah terprogram pada power supply apabila melebihi tegangan maksimal nya maka output yang diminta akan dinyatakan eror dan di tampilkan pada LCD. Ketika beban diberikan pada power supply maka hal itu akan membuat tegangan menurun dan membuat tegangan tidak stabil atau tidak sesuai yang di inginkan maka arduino yang telah di program secara otomatis akan menstabilakan tegangan output pada power supply tersebut [6][7]. 


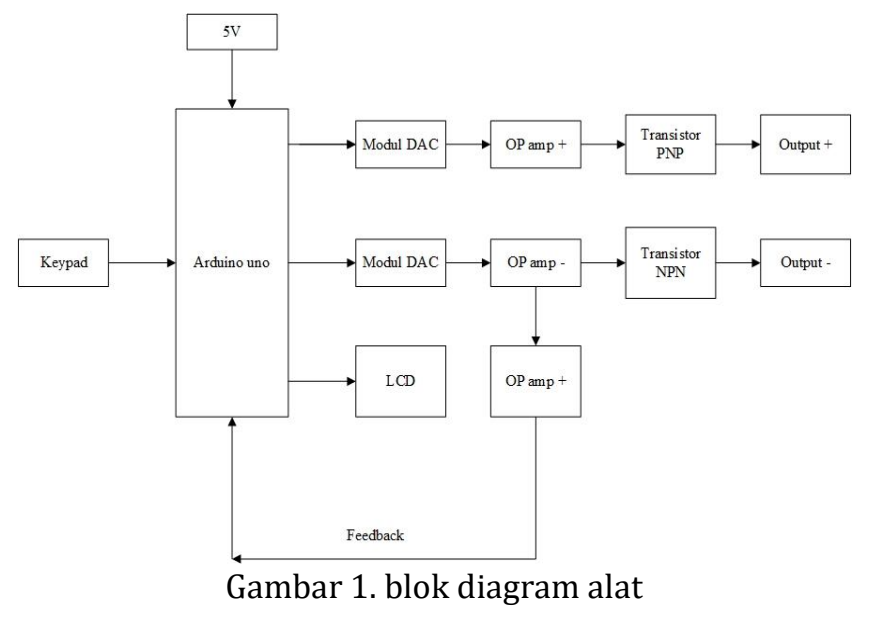

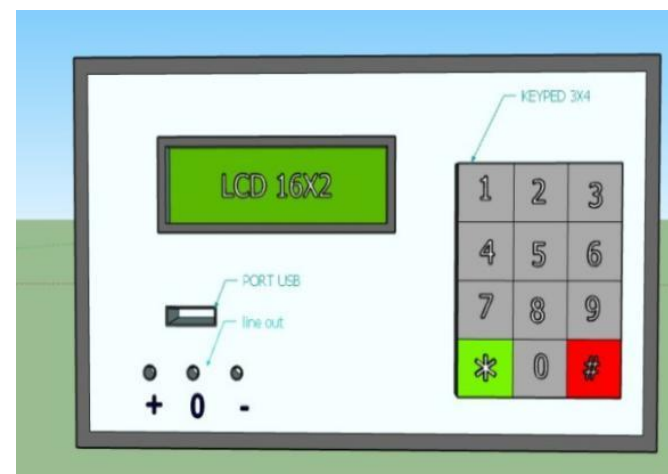

a

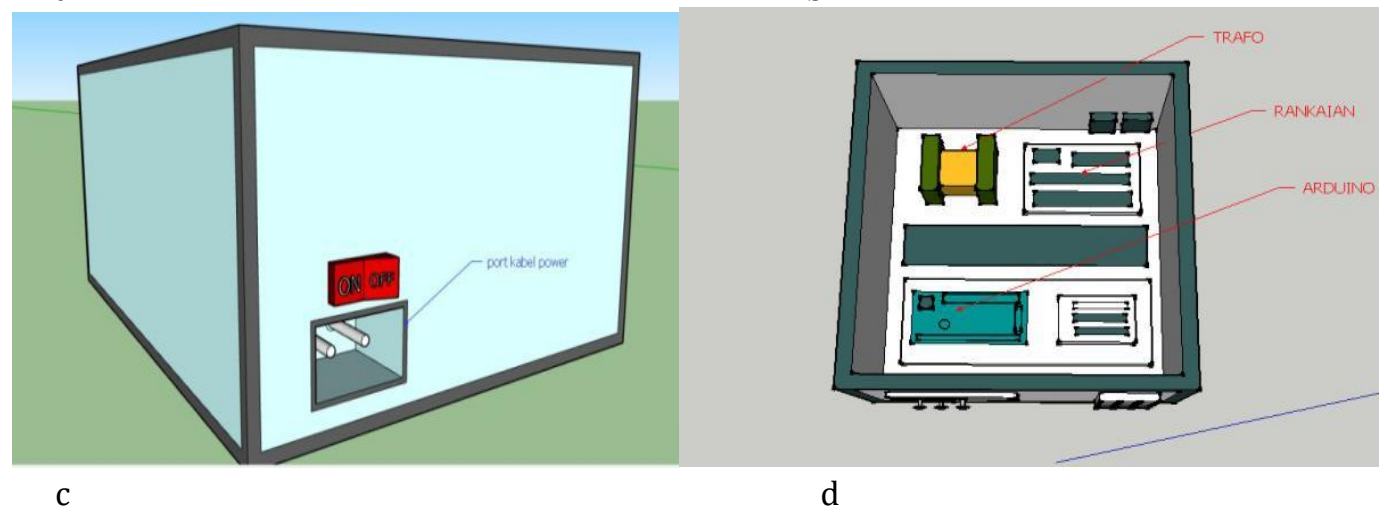

Gambar 2. Skema alat ; (a) tampak depan, (b) tampak samping, (c) tampak belakang, (d) tampak dalam 


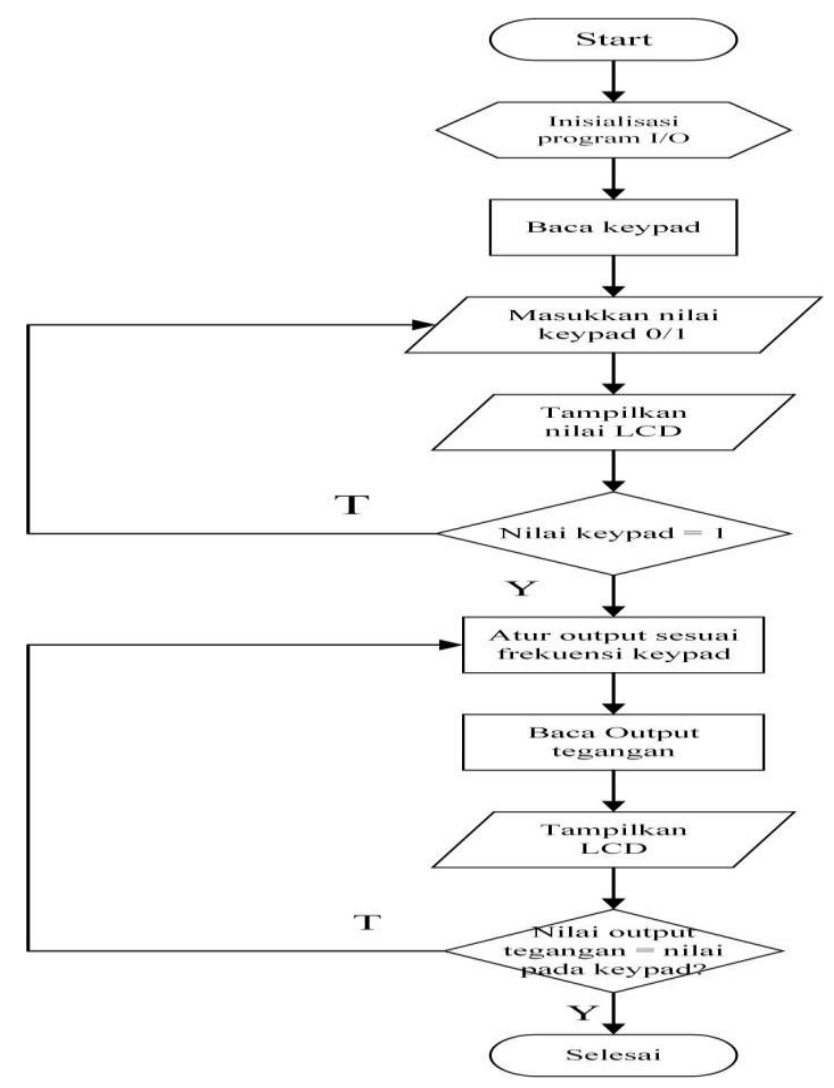

\section{Rangkaian Keseluruhan}

Gambar 3. Flowchart alat

Pada rangkaian ini, terdapat semua rangkaian elektronika yang digunakan dalam pembuatan alat. Pada gambar 7 menunjukkan rangkaian keseluruhan alat yang digunakan.

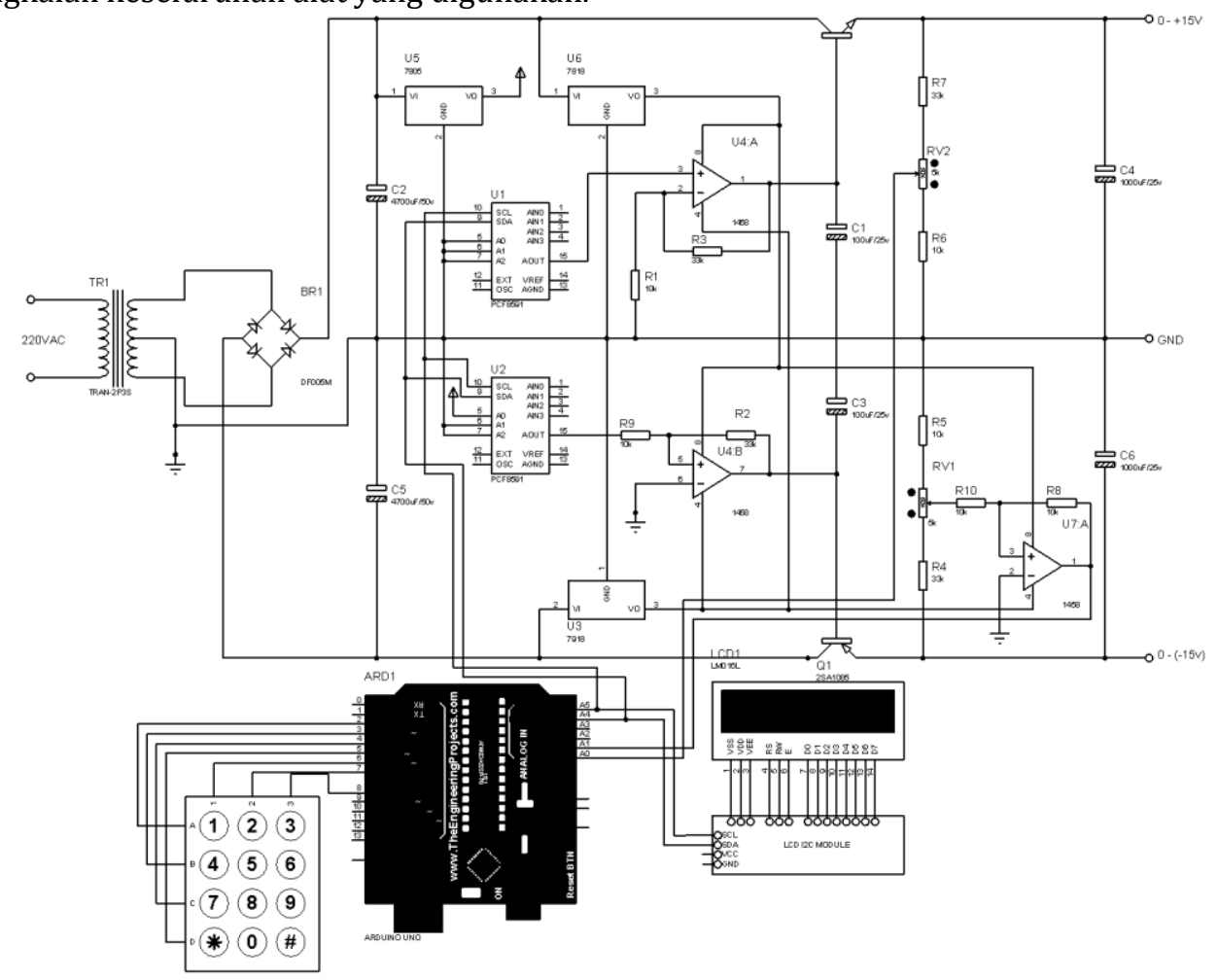

Gambar 4. Rangkaian keseluruhan 


\section{HASIL DAN PEMBAHASAN}

Pada hasil dan pembahasan akan dilakukan beberapa pengujian dan analisa pada keseluruhan bagian input dan output. Analisa akan dilakukan berguna untuk mengetahui apakah alat berfungsi dengan bauk sebagai input dan sesuai dengan yang telah direncanakan.

Tabel 1. Pengujian power supply menggunakan motor DC

\begin{tabular}{|c|c|c|c|c|}
\hline NO & $\begin{array}{c}\text { Tegangan } \\
\text { sebelum } \\
\text { diberi } \\
\text { beban }\end{array}$ & $\begin{array}{c}\text { Tegangan } \\
\text { sesudah } \\
\text { diberi } \\
\text { beban }\end{array}$ & Arus & $\begin{array}{c}\text { Lama } \\
\text { waktu } \\
\text { tegangan } \\
\text { turun }\end{array}$ \\
\hline 1 & $5,0 \mathrm{~V}$ & $4,9 \_5,0$ & 0,65 & 1 detik \\
\hline 2 & 6,0 & $5,9 \_6,0$ & 0,67 & 1 detik \\
\hline 3 & 7,0 & $6,8 \_7,0$ & 0,71 & 1 detik \\
\hline 4 & 8,0 & $7,8 \_8,0$ & 0,74 & 1 detik \\
\hline 5 & 9,0 & $8,9 \_9,0$ & 0,77 & 1 detik \\
\hline 6 & 10,0 & $9,8 \_10,1$ & 0,81 & 1 detik \\
\hline 7 & 11,0 & $10,8 \_11,1$ & 0,81 & 1 detik \\
\hline 8 & 12,0 & $4,0 \_12,0$ & 0,84 & 3 detik \\
\hline 9 & 13,0 & $4,7 \_13,5$ & 0,85 & 6 detik \\
\hline 10 & 14,0 & $9,7 \_13,5$ & 0,87 & 4 detik \\
\hline 11 & 15,0 & $1,2 \_13,5$ & 0,88 & 3 detik \\
\hline
\end{tabular}

Dari hasil pengujian yang dapat di lihat pada tabel 5 pada alat ( power supply) yang diberikan beban dapat dilihat hasilnya pada tabel diatas dimana ketika power supply tersebut diberikan beban maka tegangan akan turun dalam beberapa detik dan kemudian kembali stabil tetapi untuk perobaan teganggan mengunakan motor yang diatur pada tegangan 13 sampai 15 volt tegangan akan menurun drastis kemudian berlahan naik dan menetap pada 13,5 volt. Beban yang digunakan adalah motor DC model MY1016.

Tabel 2. Pengujian Tegangan keluaran Power Supply Berbeban Dengan Arus1,5A

\begin{tabular}{|c|c|c|c|c|c|}
\hline \multirow[t]{2}{*}{ Ohm } & \multirow[t]{2}{*}{$\begin{array}{c}\text { Ampere } \\
1,5 \mathrm{~A}\end{array}$} & \multicolumn{2}{|c|}{$\begin{array}{c}\text { Tegangan Saat } \\
\text { Berbeban }\end{array}$} & \multicolumn{2}{|c|}{$\begin{array}{l}\text { Tegangan } \\
\text { Stabil }\end{array}$} \\
\hline & & $12,0 \mathrm{~V}$ & $15,0 \mathrm{~V}$ & $\begin{array}{c}12,0 \\
V\end{array}$ & $\begin{array}{c}15,0 \\
\mathrm{~V}\end{array}$ \\
\hline 26,66 & $1,5 \mathrm{~A}$ & $6,0 \mathrm{~V}$ & $\mathrm{~V}^{5,0}$ & $\begin{array}{c}12,0 \\
V\end{array}$ & $\begin{array}{c}13,5 \\
V\end{array}$ \\
\hline 37,19 & $1,5 \mathrm{~A}$ & $3,0 \mathrm{~V}$ & $2,0 \mathrm{~V}$ & $\begin{array}{c}10,0 \\
V\end{array}$ & $\begin{array}{c}13,5 \\
V\end{array}$ \\
\hline 42,52 & $1,5 \mathrm{~A}$ & $1,0 \mathrm{~V}$ & $1,0 \mathrm{~V}$ & $8,0 \mathrm{~V}$ & $\begin{array}{c}12,0 \\
\mathrm{~V}\end{array}$ \\
\hline 66,39 & $1,5 \mathrm{~A}$ & $0,8 \mathrm{~V}$ & $0,9 \mathrm{~V}$ & $8,0 \mathrm{~V}$ & $8,0 \mathrm{~V}$ \\
\hline 86,51 & $1,5 \mathrm{~A}$ & $0,6 \mathrm{~V}$ & $0,8 \mathrm{~V}$ & $8,0 \mathrm{~V}$ & $7,0 \mathrm{~V}$ \\
\hline
\end{tabular}

Tabel 3. Pengujian Tegangan Keluaran Power Supply Berbeban Dengan Arus 2,4 A

\begin{tabular}{|c|c|c|c|c|c|}
\hline \multirow[t]{2}{*}{$\mathrm{Ohm}$} & \multirow{2}{*}{$\begin{array}{c}\text { Ampere } \\
2,4 \mathrm{~A}\end{array}$} & \multicolumn{2}{|c|}{$\begin{array}{c}\text { Tegangan Saat } \\
\text { Berbeban }\end{array}$} & \multicolumn{2}{|c|}{$\begin{array}{l}\text { Tegangan } \\
\text { Stabil }\end{array}$} \\
\hline & & 5,0 & 6,0 & 5,0 & 6,0 \\
\hline 26,66 & $2,4 \mathrm{~A}$ & 1,0 & 0,9 & 5,0 & 6,0 \\
\hline 37,19 & $2,4 \mathrm{~A}$ & 0,9 & 0,8 & 5,0 & 6,0 \\
\hline 42,52 & $2,4 \mathrm{~A}$ & 0,8 & 0,5 & 4,0 & 5,0 \\
\hline 66,39 & $2,4 \mathrm{~A}$ & 0,6 & 0,4 & 4,5 & 4,5 \\
\hline 105,51 & $2,4 \mathrm{~A}$ & 0,5 & 0,3 & 3,0 & 4,5 \\
\hline
\end{tabular}

Pada hasil pengujian tabel 6 dan 7 dapat dilihat bahwa ketika beban dinaikkan dan ditambahkan maka tegangan dari Power supply akan sulit di stabilkan dan arus maksimal dari masing masing beban tidak boleh melebihi batas maksimal, jika di paksakan dalam keadaan maksimal akan berdampak pada komponen yang ada pada power supply.

Tabel 4. Pengujian Tegangan Keluaran Power Supply Tanpa Beban

\begin{tabular}{|c|c|c|c|c|c|c|}
\hline \multirow{2}{*}{ No } & \multicolumn{2}{|c}{ LCD (V) } & \multicolumn{2}{c|}{$\begin{array}{c}\text { Clamp meter } \\
(\mathrm{V})\end{array}$} & \multicolumn{2}{c|}{ Selisih (V) } \\
\cline { 2 - 7 } & $(\mathrm{V})+$ & $(\mathrm{V})-$ & $(\mathrm{V})+$ & $(\mathrm{V})-$ & $(\mathrm{V})+$ & $(\mathrm{V})-$ \\
\hline 1 & 1.1 & 1.1 & 1.1 & 1.1 & 0 & 0 \\
\hline 2 & 2.1 & 2.1 & 2.1 & 2.1 & 0 & 0 \\
\hline 3 & 3.1 & 3.1 & 3.1 & 3.1 & 0 & 0 \\
\hline 4 & 4.1 & 4.0 & 4.1 & 4.0 & 0 & 0 \\
\hline 5 & 5.0 & 5.1 & 5.1 & 5.0 & 0 & 0 \\
\hline 6 & 6.0 & 6.0 & 6.0 & 5.9 & 0 & 0.1 \\
\hline 7 & 7.0 & 7.0 & 7.0 & 6.8 & 0 & 0.2 \\
\hline 8 & 8.0 & 8.0 & 7.9 & 7.6 & 0.1 & 0.4 \\
\hline 9 & 9.0 & 9.0 & 9.0 & 8.7 & 0 & 0.3 \\
\hline 10 & 10.0 & 10.1 & 9.8 & 9.6 & 0.2 & 0.4 \\
\hline 11 & 11.0 & 11.1 & 10.8 & 10.4 & 0.2 & 0.6 \\
\hline 12 & 12.1 & 12.0 & 11.8 & 11.7 & 0.2 & 0.3 \\
\hline 13 & 13.0 & 13.0 & 13.0 & 12.6 & 0 & 0.4 \\
\hline 14 & 14.1 & 14.1 & 14.0 & 13.5 & 0 & 0.5 \\
\hline 15 & 15.1 & 15.1 & 15.0 & 14.5 & 0 & 0.5 \\
\hline
\end{tabular}


Dari hasil pengujian alat (power supply) tanpa beban menggunakan clamp meter maka terdapat sedikit perbedaan pada clamp meter dan LCD hal ini disebabkan karena kesulitan pada saat mengkalibrasi antara hasil yang ada pada multi dan hasil yang tertera pada LCD. Namun perbedaan tersebut tidak terjadi secara keseluruhan hanya pada beberapa tegangan saja, dan pada pengujian menggunakan ociloscop tidak terdapat riak atau rippel pada tegangan yang di hasilkan.

\section{PENUTUP}

Rancang bangun power supply memiliki akuturasi yang cukup baik untuk pengendalian tegangan pada beban. Rancang bangun power supply mampu membaca tegangan DC dari 1 sampai 15 volt positif dan negatif dengan arus 3 ampere. Rancang bangun power supply dapat digunakan pada beban atau alat yang memerlukan sumber DC.

\section{REFERENSI}

[1] Putra, Fergiawan Izamas, and Ali Basrah Pulungan. "Alat Pengering Biji Pinang Berbasis Arduino." J勆V (Jurnal Teknik Elektro dan Vokasional) 6.1. 2020. 8997.

[2] Atmel . 8 bit AVR Microcontroller with 32k Bytes [4]_ System Programebel Flash .Atmega 328P datasheet. Online di ww1.microchip.com. Diakses 10 oktober 2019

[3] Blocher,richard. Dasar ElektronikaI .Yogyakarta: ANDI. 2003.
[4] Budihartono, Widodo dan Sigit firmansyah. Elektronika Digital + mikroprosesor.Yogyakarta : ANDI. 2005.

[5] Sukaya. Teknik Elektronika. Padang: Universitas Negeri Padang. 2013.

[6] PCF8591 . 8 bit $A / D$ and $D / A$ Converter. Online di www.aurel32.net.Diakses 7 agustus 2019

[7] LAB PTE - 05 (PTEL626) Jobsheet 8 ADC (Analog to Digital Converter ). Online di http://elektro.um.ac.id . Diakses 20 oktober 2019

\section{Biodata Penulis}

Genta Subni Ananda Putra, lahir di Solok, 7 Oktober 1996. Menjalani Sarjana Terapan di bidang Teknik Elektro Industri Pada Jurusan Teknik Elektro FT UNP sejak tahun 2014 - sekarang.[1]

Arizal Nabila, lahir di Bukittinggi, 21 November 1998. Menyelesaikan D3 jurusan teknik elektro Universitas Negeri Padang tahun 2019.[2]

Ali Basrah Pulungan, lahir di Hutanaingkan, 12 Desember 1974. Menyelesaikan S1 Jurusan Teknik Elektro Universitas Sumatera Utara (USU). Pendidikan S2 Bidang Teknik Tenaga Listrik di Universitas Gajah Mada (UGM) Tahun 2007. Sekarang menjadi staf pengajar dijurusan Teknik Elektro Universitas Negeri Padang. ${ }^{[3]}$ 